\title{
Transgastric ERCP with Rendezvous Technique
}

\author{
Mikkel Jessen*, Bulut M, Knuhtsen S and Bremholm Hansen L \\ University of Copenhagen, Denmark
}

*Corresponding author: Mikkel Jessen, University of Copenhagen, Ingerslevsgade 172,2. 1705 Copenhagen V, Denmark

Submission: 望January 22, 2018; Published: 望 February 12, 2018

\section{Case-Report}

Two patients with gastric bypass Roux-en-Y (GBY) presented symptoms of post-prandial upper abdominal pain. Both patients had elevated liver enzyme levels and hyperbilirubinemia. MRCP was performed on both patients demonstrating cholecystolithiasis and gallstones in the common bile duct (CBD). A combined procedure was planned for both patients with laparoscopic cholecystectomy and perioperative Transgastric Rendezvous ERCP.

During laparoscopic cholecystectomy a guidewire was introduced into the cystic duct using Kumar's grasper and placed in the duodenum. Upon transgastric introduction of the duodenoscope [1] a RX-44-autotome was loaded into the wire and brought to the papilla. The papillotome was introduced over the wire through the papilla and the guide wire removed and replaced by a Jag wire in the choledochal duct. A complete papillotomy and stone extraction was performed. Cholangiography demonstrated complete clearance of stones. Both patients were discharged within days after the procedure.

Risk factors such as age, female gender, obesity, diabetes melitus and rapid weight loss increase the risk of gallstone formation $[2,3]$. Bariatric patients have a post-operative cumulative risk of 30-50 $\%$ for formation of gallstones [2,4]. 5-10\% percent are expected to develop symptomatic gallstones, thus, requiring cholecystectomy after GBY [2,4] (Figure 1 \& 2).

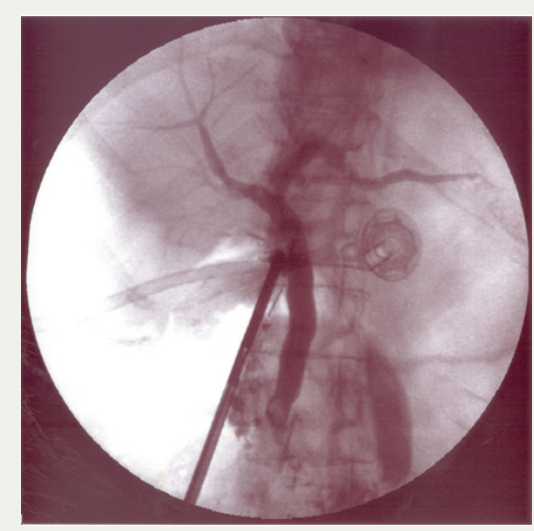

Figure 1: Peroperative cholangiografi using Kumar's grasper.

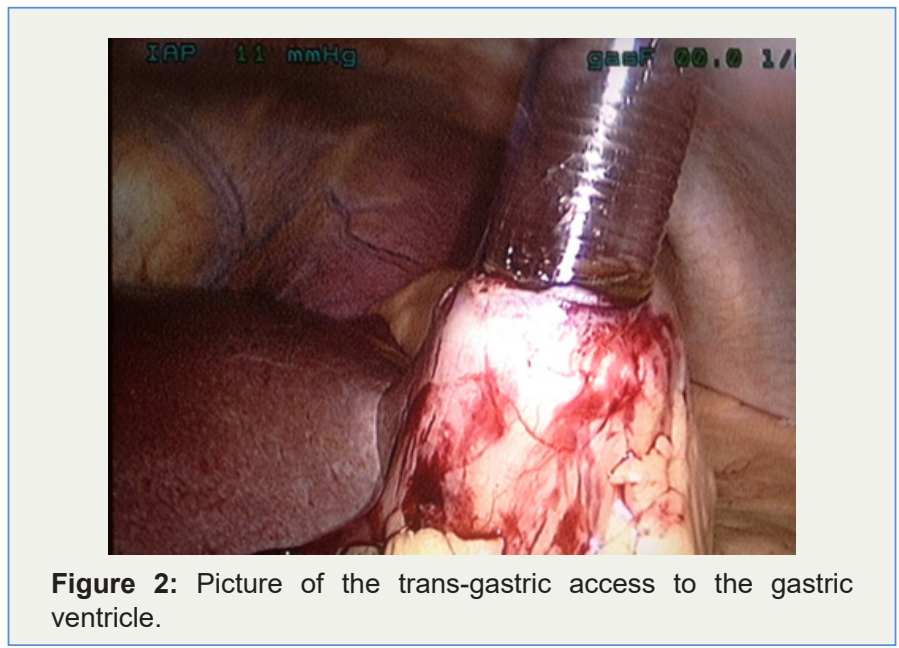

Transgastric ERCP is an established procedure for GBY patients with gallstones in the CBD [1]. The risk for post-ERCP pancreatitis (PEP) is considered the same with the transgastric procedure as with conventional ERCP with an incidence ranging from 3-10\% for PEP [5]. Comparing conventional ERCP with the Rendezvous technique indicates that the rendezvous technique reduces the risk of PEP [5].

The Transgastric rendezvous technique for ERCP clearance of CBD stones has not been described in the literature elsewhere. With a growing part of the western population undergoing GBY the number of patients with gallstones in CBD will increase. The Transgastric Rendezvous approach should be considered in these patients in order to reduce the rate of PEP.

\section{References}

1. Bertin PM, Singh K, Arregui ME (2011) Laparoscopic transgastric endoscopic retrograde cholangiopancreatography (ERCP) after gastric bypass: case series and a description of technique. Surg Endosc 25(8): 2592-2596.

2. Li VK, Pulido N, Fajnwaks P, Szomstein S, Rosenthal R, et al. (2009) Predictors of gallstone formation after bariatric surgery: a multivariate analysis of risk factors comparing gastric bypass, gastric banding, and sleeve gastrectomy. Surg Endosc 23(7): 1640-1644.

3. Brockmeyer JR, Grover BT, Kallies KJ, Kothari SN (2015) Management of biliary symptoms after bariatric surgery. Am J Surg 210(6): 1010-1016. 
4. Melmer A, Sturm W, Kuhnert B, Engl-Prosch J, Ress C, et al. (2015) Incidence of Gallstone Formation and Cholecystectomy 10 Years After Bariatric Surgery. Obes Surg 25(7): 1171-1176.
5. Swahn F, Nilsson M, Arnelo U, Löhr M, Persson G, et al. (2013) Rendezvous cannulation technique reduces post-ERCP pancreatitis: a prospective nationwide study of 12,718 ERCP procedures. The American journal of gastroenterology 108(4): 552-559.

For possible submission use the below is the URL

Your subsequent submission with Crimson Publishers will attain the below benefits

- High-level peer review and editorial services

- Freely accessible online immediately upon publication

- Authors retain the copyright to their work

- Licensing it under a Creative Commons license

- Visibility through different online platforms

- Global attainment for your research

- Article availability in different formats (Pdf, E-pub, Full Text)

- Endless customer service

- Reasonable Membership services

- Reprints availability upon request

- One step article tracking system 